\title{
STUDY OF CONDUCTIVITY BEHAVIOUR OF NEWLY SYNTHESIZED \\ TERPOLYMERIC LIGAND AND ITS POLYCHELATES WITH MN(II), FE(III), CO(II) METAL IONS
}

\author{
K. A. KHAMBORKAR ${ }^{1}$, A.V.YADGIRE ${ }^{2}$ AND A.B. KALAMBE ${ }^{3}$ \\ ${ }^{1}$ Department of Chemistry, Institute of Forensic Science, Nagpur \\ ${ }^{2}$ Department of Chemistry, Institute of Forensic Science, Nagpur \\ ${ }^{3}$ Department of Chemistry, Institute of Science, Nagpur-440 001 \\ Email: kakhamborkar@gmail.com
}

\begin{abstract}
Terpolymeric ligand was prepared by the condensation of $\mathrm{p}$ hydroxyacetophenone (P) and aniline (A) with formaldehyde (F) with 1:1:3 molar proportions in the presence of hydrochloric acid as a catalyst. Polychelates were prepared by using metal acetate, metal salts and PAF ligand in DMF medium. In the present paper, electrical conductivity of the terpolymeric ligand and its polychelates was studied over a wide range of temperature and is in the order $\mathrm{PAF}<\mathrm{Mn}$ (II)PAF $<\mathrm{Co}$ (II)PAF $<\mathrm{Fe}$ (III)PAF. The activation energy of terpolymeric ligand and its polychelates was evaluated from the plots of $\log \sigma$ versus $1 / \mathrm{T}$. On the basis of electrical conductivity measurements this terpolymeric ligand and its polychelates are ranked as semiconductors and hence useful in electronic industry.
\end{abstract}

Keywords: Electrical Conductivity, Terpolymeric Ligand, Activation Energy, Terpolymer, Chelate Polymer.

\section{Introduction}

Semiconductors have played an extremely vital role in the development of modern electronics - particularly in the communication and computer fields. It is because of this one single software, which has made it possible to microminiaturize massive electronic gadgets. The electrical conduction mechanism of the organic semiconductors and especially of the polymers is very important for the application of these materials in electronics, electro techniques and power sources. In this connection, studies were made to establish a correlation between the chemical structure and characteristics defining semi- conducting properties $^{1}$. 


\section{Review}

Semiconducting behavior was systematically developed by Brattain et al. ${ }^{2}$. Pekaln and Kotosonov have studied the electrical conductivity of phenol-formaldehyde resin ${ }^{3}$. Semiconducting behavior of polymeric ligand and its coordination polymer have been studied by electrical conductivity measurements at different temperatures ${ }^{4}$.

Patel \& Patel $^{5}$ have measured the electrical resistivity of 2,4dihydroxyactephenone-urea-formaldehyde polymeric ligand and its polychelates over a wide temperature range. They have observed the exponential variation of electrical conductivity with the absolute temperature according to the relationship

$$
\sigma=\sigma_{\mathrm{o}} \exp [-\mathrm{Ea} / \mathrm{KT}]
$$

An industrial important semiconducting materials have been reported by Kanda and Kawaguchi ${ }^{6}$.

The present study deals with electrical conductivities of PAF terpolymeric ligand and their polychelates with $\mathrm{Mn}(\mathrm{II}), \mathrm{Fe}(\mathrm{III}), \mathrm{Co}(\mathrm{II})$ ions over a wide range of temperature.

\section{Method}

All the chemicals used were of analytical reagent grade. DMF was used after distillation.

Polymeric ligand: A mixture of p-hydroxyacetophenone (0.05 mole), aniline (0.05 mole), formaldehyde (0.15 mole) in $200 \mathrm{ml} \mathrm{HCl} \mathrm{(2M)} \mathrm{was}$ refluxed on oil bath for 5-6 hours with occasional shaking. The temperature of electrically heated oil bath was controlled with the help of dimmerstat. The resinous solid product obtained was immediately removed from the flask as soon as the reaction period was over. It was then purified by dissolving in $(1 \mathrm{M})$ sodium hydroxide solution, filtered and reprecipitated by gradual drop wise addition of ice cold (2M) $\mathrm{HCl}$ with constant and rapid stirring to avoid lump formation. The PAF terpolymeric ligand so obtained was filtered, washed several times with 
hot water, dried in air, powdered and kept in vacuum desiccators over silica gel $7,8,9,10$.

Polychelates: To PAF (0.01mole) dissolved in DMF (50ml), the respective metal salt (0.005 mole) in DMF (50ml) was added slowly with stirring. The polychelate separated out on addition of saturated solution of sodium acetate. It was digested for $30 \mathrm{~min}$ on a water-bath, filtered; the solid washed with DMF and hot distilled water and dried it. The D. C. conductivity of the terpolymeric ligand and polychelates was measured in the variable temperature range. The resistance of the terpolymeric ligand and its polychelates was measured using Digital multi-meter Model DT 92080L. To prepare the pellets, terpolymeric ligand and polychelates were thoroughly grounded in agate pestle and mortar separately. It was

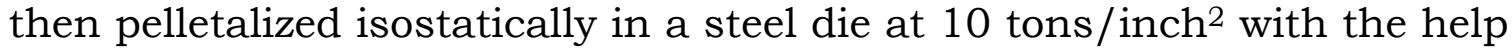
of a hydraulic press. The pellets obtained were hard and crack free. Thin layer of charcoal in acetone coating was then applied on both the side of the pellet. The average diameter of the pellet and its thickness were measured using a vernier caliper and screw gauge respectively.

\section{Result and Discussion}

The values of electrical conductivity $(\sigma)$ were obtained from the resistively values $(\sigma=1 / \rho)$. The electrical conductivity varies exponentially with the absolute temperature according to the well known relationship,

$$
\sigma=\sigma_{\mathrm{o}} \exp .\left(-\mathrm{E}_{\mathrm{a}} / \mathrm{KT}\right)
$$

Where, $\sigma=$ Electrical conductivity at temperature $\mathrm{T}$

$\sigma_{\mathrm{o}}=$ Electrical conductivity at temperature $\mathrm{T} \infty$

i. e., constant.

$\mathrm{E}_{\mathrm{a}}=$ Activation energy of electrical conduction

$\mathrm{K}=$ Boltzmann constant $\left(8.6173 \times 10^{-5} \mathrm{eV} / \mathrm{K}\right)$

$\mathrm{T}=$ Absolute temperature

The above relationship has been modified as,

$$
\log \sigma=\log \sigma_{\mathrm{o}}+\left(-\mathrm{E}_{\mathrm{a}} / 2.303 \mathrm{KT}\right)
$$


The temperature dependence of the electrical conductivity of PAF terpolymeric ligand and its polychelates is shown in figure I.

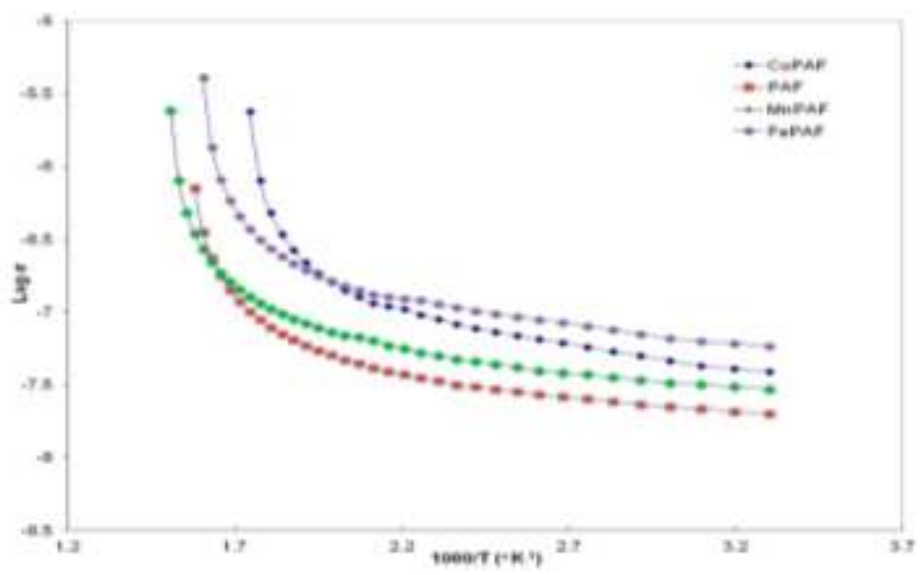

Figure 1. Temperature dependence of the electrical conductivity of PAF terpolymeric ligand and its polychelates.

Plots of $\log \sigma$ versus $1 / \mathrm{T}$ found to be linear with negative slope. The detailed relevant data on electrical conductivities and activation energies of the terpolymeric ligand and polychelates are compiled in table 1.

\begin{tabular}{|c|c|c|c|c|}
\hline $\begin{array}{c}\text { Polymeric } \\
\text { Ligands } /\end{array}$ & $\begin{array}{c}\text { Temperature } \\
\text { Polychelates }\end{array}$ & $\begin{array}{c}\text { Activation } \\
\text { Energy } \\
(\mathrm{K})\end{array}$ & $\begin{array}{c}\text { Activation } \\
\text { Energy } \\
(\mathrm{eV} / \mathrm{K})\end{array}$ & $\begin{array}{c}\text { Electrical } \\
\text { Conductance } \\
(\Omega / \mathrm{cm})\end{array}$ \\
\hline PAF & $303-423$ & $2.951 \mathrm{E}-24$ & $1.843 \mathrm{E}-02$ & $1.988 \mathrm{E}-14$ \\
\hline MnPAF & $303-493$ & $4.025 \mathrm{E}-24$ & $2.512 \mathrm{E}-02$ & $2.947 \mathrm{E}-14$ \\
\hline FePAF & $303-473$ & $4.354 \mathrm{E}-24$ & $2.717 \mathrm{E}-02$ & $5.829 \mathrm{E}-14$ \\
\hline CoPAF & $303-473$ & $5.610 \mathrm{E}-24$ & $3.502 \mathrm{E}-02$ & $3.882 \mathrm{E}-14$ \\
\hline
\end{tabular}

Table 1. Electrical Conductivities and Activation Energies of terpolymeric ligand and its polychelates

\section{Conclusions}

From the results of temperature dependence of electrical conductivity of terpolymeric ligand (PAF) and its polychelates following conclusions can be drawn 
1) At room temperature, terpolymeric ligand (PAF) has an electrical conductivity $1.9882 \times 10^{-14}\left(\Omega \mathrm{cm}^{-1}\right)$.

2) The electrical conductivity of polychelates of PAF at room temperature lies in the range of $1.9882 \times 10^{-14}\left(\Omega \mathrm{cm}^{-1}\right)$ to $5.8290 \times 10^{-14}\left(\Omega \mathrm{cm}^{-1}\right)$.

3) The electrical conductivity of PAF and its polychelates increases in the order $\mathrm{PAF}<\mathrm{Mn}(\mathrm{II})<\mathrm{Co}$ (II) $<\mathrm{Fe}$ (III) at room temperature.

4) The activation energy of electrical conductance of PAF and its polychelates lies in the range of $1.8432 \mathrm{X} 10^{-02}\left(\mathrm{eV} \mathrm{K}^{-1}\right)$ to 3.5021 X 10-02 $\left(\mathrm{eV} \mathrm{K}^{-1}\right)$.

5) The plots of Log $\sigma$ vs $1 / \mathrm{T}$ were found to be linear (Fig 1) over a wide range of temperature indicates semiconducting nature of terpolymeric ligand and polychelates ${ }^{11}$.

6) The results indicated that the electrical conductivity and the activation energy values of electrical conduction of these polychelates varies with the metal ions, which may be due to the incorporation of different metal ions in the polymeric ligand which increase the ionization tendency ${ }^{12}$.

7) The decrease in activation energy of these polymers with increase in aromatic nucleus can also be explained on the basis of availability of $\pi$ electrons in the polymers chains which increases with increase in aromatic domain in the polymers. Our observations are in good harmony with the observations made by earlier workers ${ }^{13}$.

\section{References}

Gautman F and Lyons L E, (1967). Organic semiconductors, John Wiley, New York.

Brattain W H and Garrette G G, (1955) Bell. Sust. Tech. J., 34, 129.

Pekln L A and Kotosonov A S, (1974) Konstr, Materosn, Grafita, 8, 122, Chem. Abstr., 1975, 82 98952c. 
Pancholi H B and Patel M M, (1996) J. Polym. Mater, 13, 261-267.

Patel K D and Patel M M (1993). Synth. React. Inorg. Met.-org. Chem., 23 (2), 299-325.

Kanda S and Kawaguchi S, (1961) J. Chem. Phys, 34, 1070.

Joshi R M and Patel M M, (1983) J. Macromol. Sci. Chem, A 19(5), 705.

Patel M M and Manavaian R, (1983) Indian J. Chem., 22 A, 117.

Pal T K and Kharat R B, (1989). Die Angewandte Makromolkulare Chemie, 173, 55.

Pal T K and Kharat R B, (1989) Indian J. Chem., 28A (1), 55.

Katon J E (Ed.), (1968) Organic Semiconducting Polymer, Marcel Dekker Inc., New York, 89.

Patel M M and Manavalan R, (1983). J. Macromol Sci.-Chem., 20A (4), 487.

Katon J.E, (1968) Organic Semiconducting Polymers, Marcel Dekker Inc., New York, 90. 